Selcuk Journal of Agriculture and Food Sciences

$\underline{\text { http://sjafs.selcuk.edu.tr/sjafs/index }}$

Research Article
SJAFS

(2020) 34 (3), 178-182

e-ISSN: $2458-8377$

DOI:10.15316/SJAFS.2020.213

\title{
Using The Response Surface Method to Determine Optimum Temperature and Gam Usage in Egg Storage
}

Can YAVUZ, (1D İsmail KESKIN ${ }^{1 *}$

${ }^{1}$ Selcuk University, Faculty of Agriculture, Department of Animal Science, Konya, Turkey

\begin{tabular}{|c|c|}
\hline ARTICLE INFO & ABSTRACT \\
\hline $\begin{array}{l}\text { Article history: } \\
\text { Received date: } 20.07 .2020 \\
\text { Accepted date: } 24.08 .2020\end{array}$ & $\begin{array}{l}\text { Response surface method (RSM) is a form of optimization based on the } \\
\text { creation of an empirical model for evaluating the relationship between factor } \\
\text { levels and the responses obtained therefrom. RSM is a multivariate analysis }\end{array}$ \\
\hline $\begin{array}{l}\text { Edited by: } \\
\text { İbrahim AYTEKİN; Selcuk University, } \\
\text { Turkey }\end{array}$ & $\begin{array}{l}\text { optimization method can also be used as a preliminary stage of factorial } \\
\text { experiments, since factor levels determine the optimum points before a } \\
\text { factorial experiment. In this way, since the difference between the factor levels } \\
\text { will be less, it provides more healthy results. In other words, optimization is } \\
\text { used to increase the significance and sensitivity of factor levels.In this study, }\end{array}$ \\
\hline $\begin{array}{l}\text { Keywords: } \\
\text { Central composite design } \\
\text { Face centered composite design } \\
\text { Egg } \\
\text { Optimization } \\
\text { Response surface method }\end{array}$ & $\begin{array}{l}130 \text { table chicken eggs were divided into } 9 \text { groups according to their storage } \\
\text { temperatures and percentages of coating gam arabic matter. Weight losses } \\
\text { during the } 28 \text {-day storage period of eggs were calculated. The eggs were } \\
\text { weighed on the } 7 \text { th day, the } 14 \text { th day, the } 21 \text { st day, and the } 28 \text { th day. After the } \\
\text { study was completed, the differences of the weights on the first day and } 28 \text { th } \\
\text { day were calculated. While applying RSM, Central Composite Design trial } \\
\text { pattern was used. As a result of the analysis, optimum storage temperature and } \\
\text { gam arabic composition were determined for egg storage with RSM. } \\
\text { According to the results of the statistical analysis, at the end of the } 4^{\text {th }} \text { week, it } \\
\text { was determined that the optimum storage temperature and gum substance } \\
\text { composition for the minimum egg weight loss }\left(1.58 \text { g) were } 7.64-8.24{ }^{\circ} \mathrm{C} \text { and }\right. \\
15 \% \text {. When the results of the study and the results obtained from the analysis } \\
\text { are compared, it is thought that RSM has obtained an intermediate dose } \\
\text { estimation for the minimum egg weight loss in optimization of egg } \\
\text { preservation conditions and this may be beneficial in the field of animal } \\
\text { breeding. }\end{array}$ \\
\hline
\end{tabular}

\section{Introduction}

Foods of animal origin are more important than foods of vegetable origin in meeting the energy, protein, vitamins and minerals that the human body needs. Chicken eggs are a relatively inexpensive animal protein source compared to other animal foods. In addition to being a quality food source due to its high protein content and sufficient essential amino acids, chicken eggs and chicken meat are consumed more than red meat by those who have a balanced nutrition awareness. However, since egg storage conditions are not developed in our country, eggs are mostly consumed fresh. Therefore, freshness must be preserved until the chicken eggs reach the consumer. Determination of physical, chemical and microbiological changes de- pending on different temperature conditions in eggs to be consumed fresh is very important in terms of both preventing economic loss, protecting public health and consumer satisfaction.

Optimization; is a term that enables achieving certain targets (such as reducing costs, increasing profitability, increasing capacity utilization) by using the resources in a system (such as labor, time, process, raw material, equipment) as efficiently as possible (Banga et al., 2003).

In other words, optimization is a tool used for high process efficiency and product quality in processes. It is to choose the best alternative among the alternatives possible under certain conditions. The aim of optimization is to increase efficiency by using limited production resources that will provide minimum cost and maximum profit. Response surface method (RSM) is a

\footnotetext{
* Corresponding author email: ikeskin@selcuk.edu.tr
} 
statistical technique for finding the best result possible (Saguy et al., 1984).

RSM explores the relationships between various explanatory variables and one or more response variables. The method was introduced by Box \& Wilson in 1951 (Box \& Wilson, 1992). The main idea of RSM is to use a series of experiments designed to obtain an optimal response. To do this, researchers propose a quadratic polynomial model. They accept that this model is only an approach, but they use it, because such a model is easy to guess and apply even if little is known about the process. RSM is applied after determining minor factors that have little or no effect on the response (Anonymous, 2018). In the first stage, it is necessary to determine the factors that are thought to have an effect on the response variable. The levels of these factors should then be determined.

In this study, by using RSM, it is aimed to determine the best preservation temperature and gum arabic percentages that will give the least weight loss during the 28-day storage period.

\section{Materials and Methods}

\subsection{Material}

One hundred thirty uniform chicken eggs from a local egg supplier were used as research material.

\subsection{Method}

Eggs were stored at $4{ }^{\circ} \mathrm{C}, 14^{\circ} \mathrm{C}$ and $24^{\circ} \mathrm{C}$, covered with $3 \%, 9 \%$ and $15 \%$ gum arabic coater. After the eggs covered with the gum arabic substance have dried out, they are divided into groups according to different temperature and gum arabic mixture percentages as in Table 1. The stored eggs were weighed and weight losses during the storage period were determined. Face-Central Composite Design was used for analysis.

Table 1

Egg groups according to their temperatures and gum arabic percentages

\begin{tabular}{cccc}
\hline \multirow{2}{*}{ Gum Arabic(\%) } & \multicolumn{3}{c}{ Storage Temperature $\left({ }^{\circ} \mathrm{C}\right)$} \\
\cline { 3 - 4 } & 4 & 14 & 24 \\
9 & 10 & 10 & 10 \\
9 & 10 & 50 & 10 \\
15 & 10 & 10 & 10 \\
\hline
\end{tabular}

\subsection{Response Surface Method}

The Response Surface Method (RSM) is a statistical method that is useful for modeling and analyzing factors that affect a response by several variables, and the aim is to optimize this response (Teja \&Muneiah, 2018). RSM was originally established to model experimental responses and then started to be used to model numerical experiments (Box \& Draper, 1987). The difference is in the error type generated by the response. In physical experiments, inaccuracies may be due to reasons such as measurement errors or various errors made by the observer, while in computer exper- iments numerical noise is a result of discrete representation of iterative processes, rounding errors, or continuous physical events. The errors are assumed to berandom in RSM (Namdev et al., 2014). One of the most important features of RSM is that it optimizes the factors that are thought to affect the response variable effectively by using appropriate mathematical and statistical methods (Montgomery, 2001).

While all treatment combinations have to be included in the experiment in factorial trials, not all factor combinations are used as RSM will be based on optimum points. The unexamined combinations can be used by researchers since they do not cause any loss of information (Y1lmaz, 2002). For example, in a factorial trial with 3 factors and 3 levels, $3^{3}=27$ treatment combinations are required, while $2^{\mathrm{n}}+(2 \mathrm{n}+1)=2 \times 3+(2$ $\times 3+1)=15$ treatment combinations is sufficient in RSM (Y1lmaz, 2002).

While a model can be created using multivariate regression models in RSM, many variables that affect the response can be examined together, and the response can be defined in the best way by making the least number of experiments. Allowing the determination of the optimum point by taking into account a large number of responses, RSM stands out among other optimization methods. If the relationship between dependent and independent variables is linear, then it makes use of the following linear regression equation (Montgomery, 2001).

$$
Y=\beta_{0}+\beta_{1} X_{1}+\beta_{2} X_{2}+\cdots+\beta_{n} X_{n}+\varepsilon
$$

If the system has curvature, a higher order polynomial should be used, such as a second order model. If the relationship between dependent and independent variables is not linear, that is, if the system has curvature, a higher order polynomial, such as a second order model, should be used. It is calculated with the help of nonlinear regression (quadratic) equation (Montgomery, 2001).

$$
\begin{aligned}
Y=\beta_{0}+\beta_{1} X_{1}+ & \cdots+\beta_{n} X_{n}+\beta_{11} X_{1}+\beta_{11} X_{1}^{2}+\cdots \\
& +\beta_{n n} X_{n}^{2}+\beta_{11} X_{1}^{2}+\cdots \\
& +\beta_{12} X_{1} X_{2}+\cdots+\beta_{n-1, n} X_{n-1} X_{n}+\varepsilon
\end{aligned}
$$

\subsection{Central Composite Design}

The system needs a more detailed model to optimize the process and show the relationship between response and the values of the factors (Brereton, 2003). CCD is a very suitable design model for second-order models. Box \& Hunter (1957) suggested that the quadratic response surface design should be rotatable. Central Composite Design can be rotated by choosing " $\alpha$ ". There may be occasions when the region of interest may sometimes be desired to be cubic rather than global. In such cases, Face-Centered Central Composite Design, which is a derivative of Central Composite Design, is used. In Face-centered Center Composite Design, $\alpha= \pm 1$. Face-Centered Central Composite Design is not rotatable. The Face-Centered Center Composite Design does not require as much center points as the global CCD (Montgomery, 2001). 


\section{Results and Discussion}

For the 4-week preservation of eggs at different temperatures and gum arabic concentrations, the predicted results obtained by the response surface method are shown in Table 2.

Table 2

Top 5 predictions for fourth week results

\begin{tabular}{ccccc}
\hline Results & ${ }^{\circ} \mathrm{C}$ & $\begin{array}{c}\text { Gum } \\
\text { Arabic }(\%)\end{array}$ & $\begin{array}{c}\text { Weight } \\
\text { loss }(\mathrm{g})\end{array}$ & $\begin{array}{c}\text { Composite } \\
\text { Desirability }\end{array}$ \\
\hline 1 & 7.64 & 15.00 & 1.58 & 0.92 \\
2 & 8.04 & 15.00 & 1.58 & 0.92 \\
3 & 4.00 & 14.12 & 1.73 & 0.90 \\
4 & 11.35 & 9.89 & 2.04 & 0.86 \\
5 & 12.31 & 4.54 & 2.52 & 0.79 \\
\hline
\end{tabular}

When Table 2 is examined, it is determined that the minimum weight loss $(1.58 \mathrm{~g})$ in eggs is the conditions where the temperature is $7.64{ }^{\circ} \mathrm{C}$ and 8.04 , and the gum arabic concentration is $15 \%$. Composite Desirability value was found to be 0.92 for these predictions. The remarkable point here is that the weight loss in the egg increases with the increase of the temperature and the decrease of the gum arabic substance.

It was determined that the residues obtained as a result of preserving the eggs at different temperatures and gum arabic concentrations for 4 weeks showed normal distribution (Figure 1). When the Figure 1 is examined, it is seen that the residuals (the difference between the real values and the predicted values) show a normal distribution.

The figure showing the interaction of different amounts of gum arabic and temperature values is given in Figure 2.

Figure 3 shows the effects of temperature and gum arabic separately on the response. When the temperature and gum are considered separately in the figure, it is seen that the weight loss in the egg is less as the temperature decreases and the amount of gum increases at the end of the fourth week.

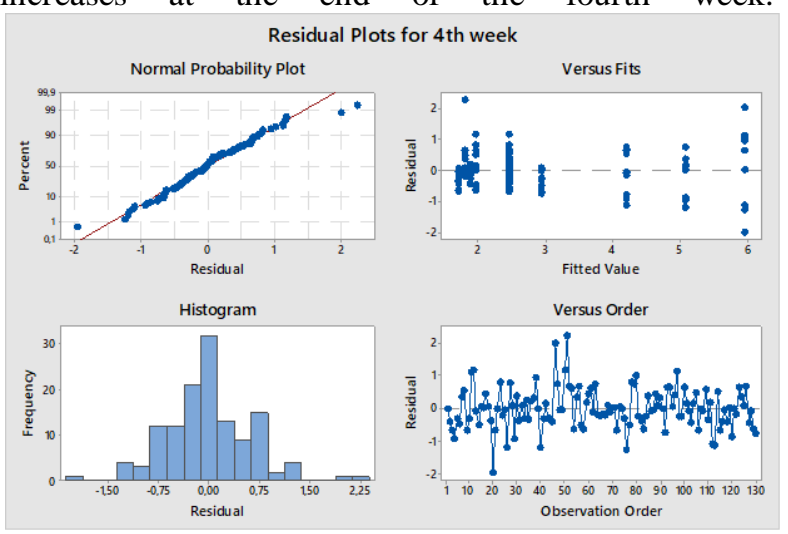

Figure 1

Residual plots for fourth week storage results

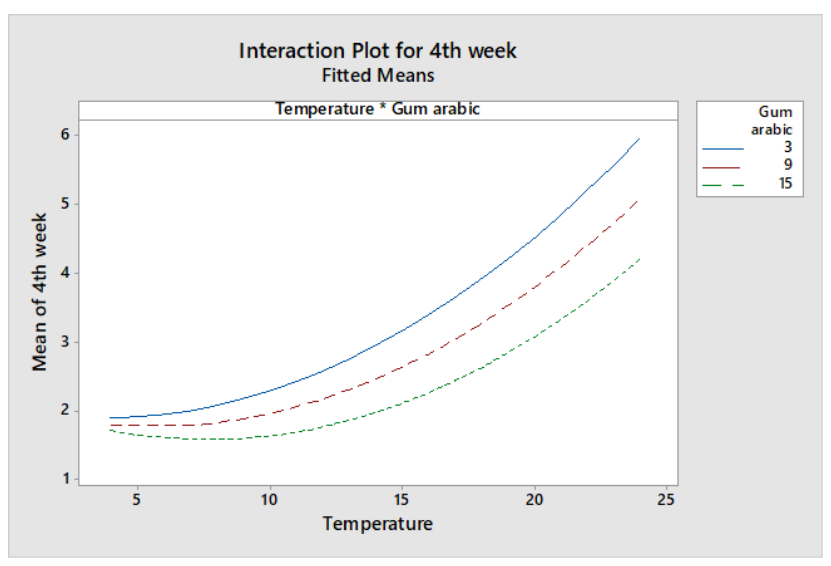

Figure 2

Interaction plot for fourth week results

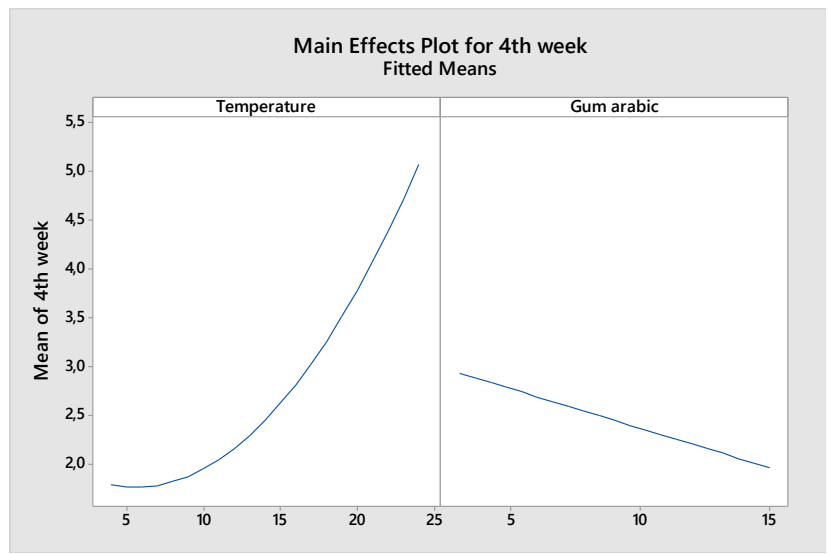

Figure 3

Main effects plot for fourth week

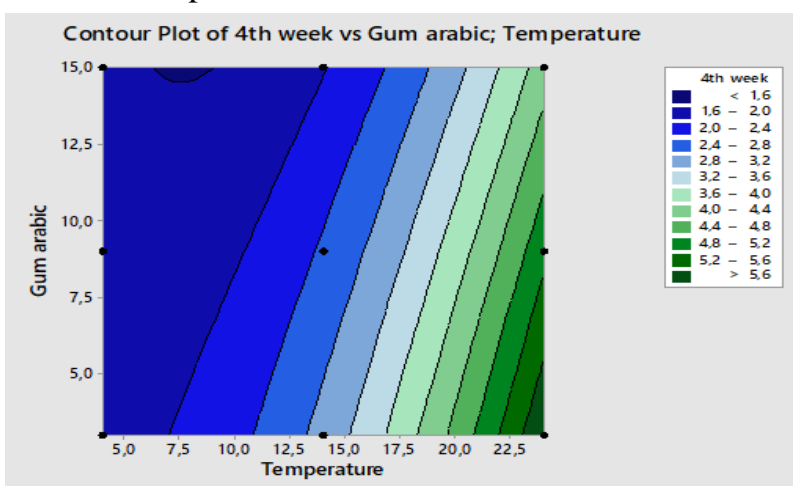

Figure 4

Display of egg weight loss with contour chart for the fourth week

When Figure 4 is examined, the region where egg weight loss is optimum is shown in dark blue $(<1.6)$. It can be seen that this region is approximately at $7-8{ }^{\circ} \mathrm{C}$ and $14-15 \%$ gum arabic.Figure 5 shows the surface graph of the fourth week results, and Figure 6 shows the optimum gum and temperature values for egg weight loss. 


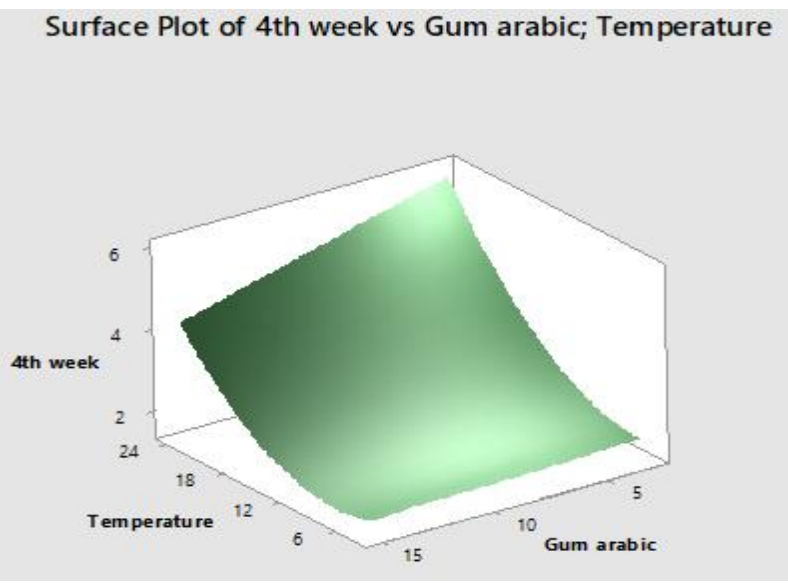

Figure 5

Representation of the results of the fourth week with surface graph

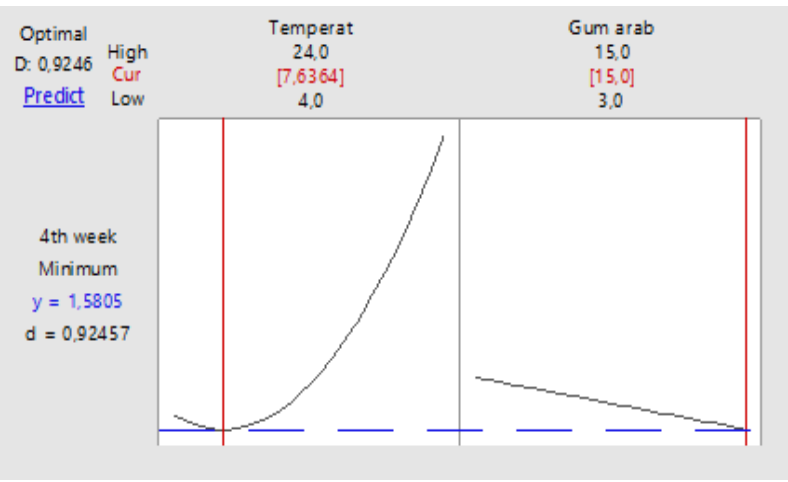

Figure 6

Graph showing the optimization of the fourth week results

When Table 2 is examined, the best predicted value for the 4 th week results was determined as the conditions where the temperature was $7.64{ }^{\circ} \mathrm{C}$ and the gum arabic concentration of $15 \%$ with a weight loss of 1.58 grams. Composite desirability was found to be 0.92 for this estimate.

\section{Conclusion and Suggestions}

Although the egg can partially protect itself against microbiological deterioration with its natural structure, this is not enough. For this reason, eggs that are not stored in appropriate storage conditions lose their freshness and lose quality. There are some important losses in egg quality in the process that the egg passes from production until it reaches the consumers. Therefore, various storage and preservation methods are applied to increase the resistance against deterioration in the egg. Among these methods, common uses include dipping, preservation in cold stores, cryopreservation, and preservation with preservatives.

The purpose of preserving with preservatives is to reduce the oxygen inflow into the egg and the carbon dioxide output from the egg. For this purpose, paraffin coating and shell coating processes are applied. Since the cost of the gum arabic used in this study is low, easily available and easy to apply, it is recommended to be used as a coating agent.

The optimum weight loss for eggs was predicted to be $1.58 \mathrm{~g}$ after four weeks of storage, and the conditions providing this condition were found to be about $7.64{ }^{\circ} \mathrm{C}$ and $15 \%$ of the gum. Desirability for this result was calculated as 0.92 .

When the eggs were stored for 28 days, the optimum point for the temperature factor was calculated as $7.64{ }^{\circ} \mathrm{C}$, an intermediate dose not addressed in the trial, instead of the lowest level of $4{ }^{\circ} \mathrm{C}$. It has been observed that the gum arabic substance should be used from the highest limit discussed in this study. According to RSM, when these conditions are met, the predicted minimum weight loss is calculated as $1.58 \mathrm{~g}$. An egg with an average of $65 \mathrm{~g}$ will have an average weight of $63.42 \mathrm{~g}$ with the loss of 4 weeks storage. If the condition where the temperature is $4{ }^{\circ} \mathrm{C}$ and the gum is $15 \%$ as a storage condition is examined, the obtained value is predicted as $1.71 \mathrm{~g}$ with 0.90 desirability degree. Both the desirability and weight loss of the response optimized by RSM are better than $4{ }^{\circ} \mathrm{C}$ and $15 \%$ gum arabic. Considering these results, when an average of $65 \mathrm{~g}$ egg is kept in optimum conditions, it is foreseen that it will not change the quality criterias of the class A egg published in the Turkish Food Codex Egg Communique. In case the storage conditions were $24{ }^{\circ} \mathrm{C}$ and $3 \%$ gamut, the weight loss was predicted as $5.95 \mathrm{~g}$. In this case, an average of $65 \mathrm{~g}$ of eggs will fall to $59.05 \mathrm{~g}$ and there will be a change in the quality classification. Therefore, determination of optimum storage conditions is an important consideration for both the consumer and the manufacturer. In cases where it is not known how long the storage will take, it will be in the manufacturer's interest to store the eggs with the optimum conditions for each week in any future change in storage period by determining a common optimum point within 4 weeks. The study on this method in the field of zootechnics is limited. The cost of the smallest calculation errors to be made in these sectors can be huge. While mistakes in the ration go to animal losses, mistakes in the food and construction industry can lead to material and life losses extending to human life. The work to be carried out in such risky sectors should be carried out with the utmost care and the highest possible efficiency. The experiments carried out until the optimum point is the most important factor affecting the cost and result.

While preparing poultry and dairy cattle rations that require precise calculation in the livestock field, it may be possible to obtain the highest possible yield from animals by preparing a more optimum feed mixture with fewer experimental materials using RSM. In the field of animal breeding, it can help enables the simultaneous evaluation of the factors and determination and subtraction of the unimportant factors in the optimization of cold storage conditions. It also contributes to the examination of the results with the help of various graphics. 
It can be used to help where it is necessary to predict the optimum points with less trial material, optimizing the response from factor levels that are not tested in experiment, making new optimums based on the changing levels of the factors, RSM may be recommended.

In cases where it is necessary to predict the optimum points with less trial material, RSM can be recommended in such cases, by optimizing the response from the factor levels not tested in the experiment and making it possible to make new optimities according to the changing levels of the factors.

\section{Acknowledgement}

This research was prepared from the Master of Science Thesis (in Selcuk University) entitled "Using The Response Surface Method to Determine Optimum Temperature and Gam Usage in Egg Storage". This research was supported by a grant from Center of Scientific Research Project of Selçuk University (BAP Project Number: 19201068).

\section{References}

Anonymous (2018). Response surface methodology,Wikipediahttps://en.wikipedia.org/wi ki/Response_surface_methodology: [20.06.2020].

Banga JR, Balsa-Canto E, Moles CG, Alonso AA (2003). Improving food processing using modern optimization methods.Trends in Food Science \& Technology 14(4): 131-144.

Box GE, Hunter, JS (1957). Multi-factor experimental designs for exploring response surfaces.The Annals of Mathematical Statistics 28(1), 195-241.

Box GE, Draper NR (1987). Empirical model-building and response surfaces, Wiley New York, p.
Box GE, Wilson KB (1992). On the experimental attainment of optimum conditions, In: Breakthroughs in statistics, Eds: Springer, p. 270310.

Brereton RG (2003). Chemometrics: data analysis for the laboratory and chemical plant, John Wiley \& Sons, p.

Montgomery DC (2001). Response Surface Methodology: Process and Product Optimization Using Designed Experiments, USA, John Wiley \& Sons, p. 427-457.

Namdev V, Singh AK, Patidar P, Pradhan M (2014). Multi-criteria Decision Making for the Optimization of Machining Process Parameters in EDM.

Saguy I, Mishkin MA, Karel M, Teixeira AA (1984). Optimization methods and available software. Part 1, Critical Reviews in Food Science \& Nutrition 20(4): 275-299.

Sanders AM, Edwards Jr HM, Rowland III GN (1992). Calcium and phosphorus requirements of the very young turkey as determined by response surface analysis.British journal of nutrition 67(3): 421-435.

Teja BS, Muneiah T (2018). Mechanical Characterization, Influence of Process Parameters and Magnetic Field on Machining Characteristics of $\mathrm{Al} / \mathrm{Cu}$ Metal Matrix Composites in EDM. International Journal of Scientific Engineering and Technology Research 1832-1836.

Yilmaz MT (2002). Response Surface Modelling For The Effect Of Nitrite, Glucono Delta Lactone And Ascorbic Acid On Various Characteristics Of Turkish Style Fermented Sausage, Ylldiz Technical University, Institute of Science, Food Engineering Department. Istanbul Turkey. 